Research Article

\title{
Breeding Performances of the European Blackbird (Turdus merula) in Morocco: Habitat Selection, Breeding Phenology, and Breeding Success
}

\author{
Abderahim El Hassani ${ }^{D}$, , Ismail Mansouri ${ }^{1}$, ${ }^{1}$ Wafae Squalli ${ }^{1},{ }^{1}$ Abdelbari El Agy $\left(\mathbb{D},{ }^{1}\right.$ \\ Amine Assouguem $₫,{ }^{1}$ Kenza Bouayad, ${ }^{1}$ Abdellah Markou, ${ }^{2}$ Mohamed Mounir $₫{ }^{3}{ }^{3}$ \\ Hamid Achiban, ${ }^{4}$ Mohamed Dakki $15,{ }^{5}$ and Lahsen El Ghadraoui ${ }^{1}$ \\ ${ }^{1}$ Laboratory of Functional Ecology and Genie of Environment, Faculty of Sciences and Technology, USMBA, Fez, Morocco \\ ${ }^{2}$ Laboratory of Bio-Geosciences and Materials Engineering, Hassan II University, Casablanca BP 50069, Morocco \\ ${ }^{3}$ Laboratory of Biotechnology and Valorisation of Phytogénétics Resources, Faculty of Sciences and Technics, \\ Sultan Moulay Sliman University, Beni Mellal, Morocco \\ ${ }^{4}$ Laboratory of Geo-environmental, Analysis Planing-Sustainable Development, Faculty of Sciences Dhar El Mahraz, USMBA, \\ $\mathrm{Fez}$, Morocco \\ ${ }^{5}$ Laboratory of Geo-biodiversity and Natural Heritage, Scientific Institute, Mohammed V University, Av. Ibn Battota, \\ Rabat 10 BP 703, Morocco
}

Correspondence should be addressed to Ismail Mansouri; mankhori@gmail.com

Received 14 May 2021; Accepted 10 July 2021; Published 19 July 2021

Academic Editor: Marco Cucco

Copyright $(2021$ Abderahim El Hassani et al. This is an open access article distributed under the Creative Commons Attribution License, which permits unrestricted use, distribution, and reproduction in any medium, provided the original work is properly cited.

\begin{abstract}
The European Blackbird (Turdus merula) is a widespread species. In Morocco, available knowledge on this species is limited to a few descriptive pieces of information with no detailed data provided. With climate change and the intensification of agricultural activities, the study of the breeding performances of this species is indispensable for management purposes. This study investigates breeding biology, nesting habitats, breeding chronology, and reproductive success of the European Blackbird in both apple orchards and surrounding woody vegetation at Ait Ayach (Morocco) between March and August 2016. We monitored weekly nest status, nesting sites, breeding dates, and failure factors. Results showed that the European Blackbird nests mainly in apple orchards, on Golden Delicious and Starkrimson Delicious trees. Nest height above the ground was $214.15 \pm 0.09 \mathrm{~cm}$. Blackbird nests were cup-shaped with medium size dimensions and built from twigs, including dry leaves, stems, and roots walled by the mud. Breeding activities started firstly by nest construction during the last week of April, secondly by egg laying during the first week of May, and thirdly by hatching during the second week of May. Among the 74 surveyed nests, $100 \%$ were active during the nesting phase and $88.38 \%$ of eggs have succeeded during the incubation phase. In total, $69.03 \%$ of chicks have been emancipated. In short, $15.9 \%$ of clutches were attacked by predators, $14.35 \%$ of clutches were failed due to nest desertion, and $8.75 \%$ of chicks were dead. Our study provides the first and only detailed data on reproductive parameters of the European Blackbird in Moroccan ecosystems. Data collected from this study provide valuable information for long-term monitoring of the Moroccan Blackbird population. Additionally, our data offer a possibility of large-scale comparative studies of the reproductive ecology of the Blackbird species.
\end{abstract}

\section{Introduction}

Studies on breeding bioecology differ from simple observations of some breeding aspect inventories to detailed studies based on monitoring of nests and the nestlings in avian species $[1,2]$. Data resulted from these studies are crucial for the development of avian life-history theory and the employment of adequate conservation management for 
these species and their environments [3]. Equally, current avian research studies have shown distinctive life-history patterns and breeding tactics, permitting theories about the evolution of breeding bioecology and increasing the efficiency of conservation policies [4].

Although recent years have witnessed a massive advance in quantity and quality of studies analyzing the breeding biology of some common and rare bird species, mainly in the European and North American continents [5], a large percentage of the avifauna species remains poorly unknown in terms of reproductive biology and breeding success $[6,7]$, mainly in Africa, despite the importance of this continents for resident and migratory birds $[7,8]$.

The European Blackbird Turdus merula is a common breeding bird all over Europe, North Africa, Asia, and Australia [9-14]. Generally, the European Blackbird is categorized as one of the most widespread passerines in the Western Palearctic zone [15]. However, the Blackbird selects breeding habitats in farmlands, woodlands, and suburban environments $[11,12,14,16]$.

In North Africa, T. merula is mainly reported in Algeria, Tunisia, and Morocco $[12,14]$. In Algeria and Tunisia, the European Blackbird is documented in urban zones, orchards, and forests $[12,14]$. On the contrary, in Morocco, data on T. merula are rare and fragmented [17]. The species is only reported as breeders in few habitats without any information on breeding biology or reproductive success [18]. However, with the recent intensification of farming activities and changes in climatic conditions [19], the understanding of breeding performances of such species is urgently required.

In this study, we used field investigations to examine the breeding biology of the European Blackbird in Moroccan ecosystems. We investigated the patterns of breeding biology, breeding chronology, nesting sites, and placement inside farmlands and woodlands. Equally, we studied breeding success and the most relevant failing factors. All these studied features are proposed to fill the gap of lacking data about this common bird in Morocco and North Africa. In addition, Morocco is considered as a migratory route, stopover, and staging area for millions of migratory birds that travel between Europe and Africa [6, 20]; therefore, the understanding of any biological aspects in Morocco will enhance and facilitate the adoption of regional or local conservation measures.

\section{Materials and Methods}

2.1. Study Area. Fieldwork was conducted in the Ait Ayach rural area, situated at Midelt Province, at the foot of Ayachi Mountain. Geographically, the study zone (Figure 1) was at a high altitude ranging between 1300 and $1600 \mathrm{~m}$ upon sea level (Mansouri et al.). The study zone is characterized by an arid cold climate, and the precipitation regime is marked by variable and low rain. The annual average precipitations and temperature are about $29^{\circ} \mathrm{C}$ and $89 \mathrm{~mm}$ successively.

Two types of habitats were studied: 16 apple orchards (farmlands) with an estimated surface of $3.5 \mathrm{ha}$, and woodlands, including riparian habitats and forest plantations in form of hedgerows surrounding apple orchards.
2.2. Data Collection. We searched for nests and breeding pairs from early March to late August 2016, using parental behavioral cues and Common Birds Census (CBC) methodology [6]. Inside apple orchards, breeding parameters (nests or breeding couples) were investigated line by line based on the tree-lines of apple orchards [21, 22] (Figure 2). In hedgerow woodlands, nests were explored with a walked transect of a few $\mathrm{km}$, depending on the surface of the monitored orchard. Visits were done weekly from 06.00 to 18.00 hours.

To describe nesting sites and nest placement, we recorded nests inside orchards, in the periphery of orchards, nesting-tree type, nesting-tree height, nest height above the ground, and nest distance to central trunk (Figure 2). Nest dimensions, including nest big diameter, small diameter, and cup depth, were also measured. In parallel, breeding chronology counting nesting (first nest/season), laying (first eggs/season), and hatching (first chicks/season) dates were documented. Finally, nest status (three categories: newempty, eggs, or chicks) and failure factors (four categories: desertion, predation, destruction, or death of clutch) were noted. All measurements were realized during the morning where birds were out to search for food.

2.3. Statistics. Breeding success rates were evaluated by the calculation of success nests (active nests/built nests), hatched eggs (hatched eggs/laid eggs), and survived chicks (chicks leaving their nests/fledged chicks). Clutch size was calculated as the number of laid eggs/total active nests. Preferences toward nesting trees were calculated by percentage (number of nest per supporting tree/all nests). Breeding dates were accumulated per week due to the lack of precision (sometimes we found built nests, laid eggs, or fledged chicks after their initiations).

We checked for normality and homogeneity of variance for all variables by the Kolmogorov-Smirnov test. Correlations among nest dimensions were tested with the Pearson correlation coefficient. The difference in breeding success rates among breeding phases (nesting, laying, and hatching) was tested by the ANOVA one-way test, considering the 16 breeding orchards. Relationships between nest height and supporting tree height ( $n=74$ nests) and between nesting dates, laying, and hatching chronology were assessed using Generalized Linear Models (GLMs). Firstly, the nest height was considered as the dependent variable and the supporting tree as predicting variable. Secondly, the nesting dates were defined as governing variables, while laying and hatching as dependent variables. Data were analyzed in STATGRAPHICS Centurion software, version XVI. I, and results were given as sample size and mean \pm SD.

\section{Results}

3.1. Selection of Nesting Site and Placement. The European Blackbird nests were built in farmlands and woodlands. $95.51 \%$ of nests were recorded in apple orchards $(49.25 \%$ on Starkrimson Delicious and $46.26 \%$ on Golden Delicious) and $4.49 \%$ in hedgerow woodlands $(2.99 \%$ on wild rose and $1.49 \%$ on poplar). 


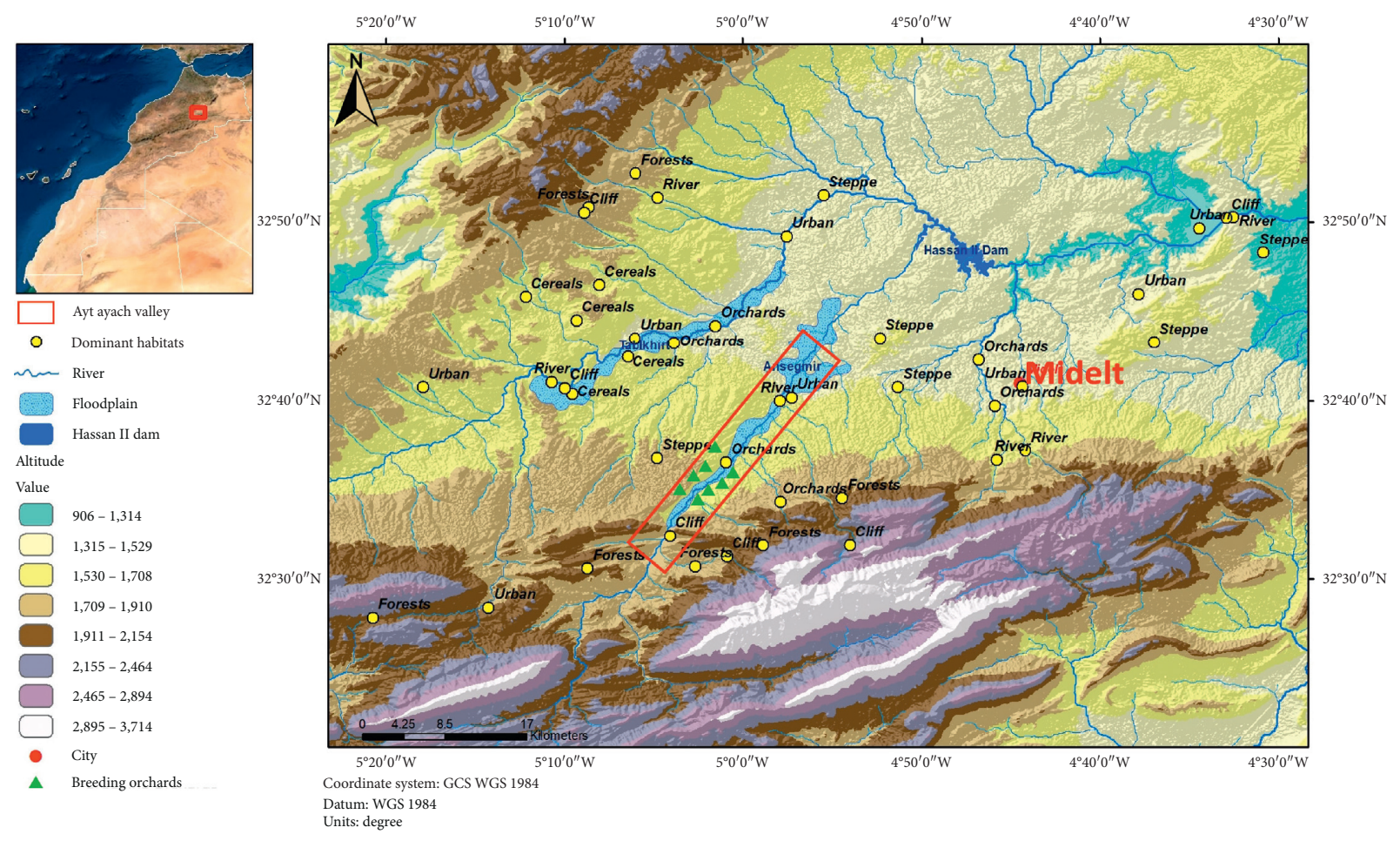

Figure 1: Location of the studied habitats at Ait Ayach zone during 2016 season.

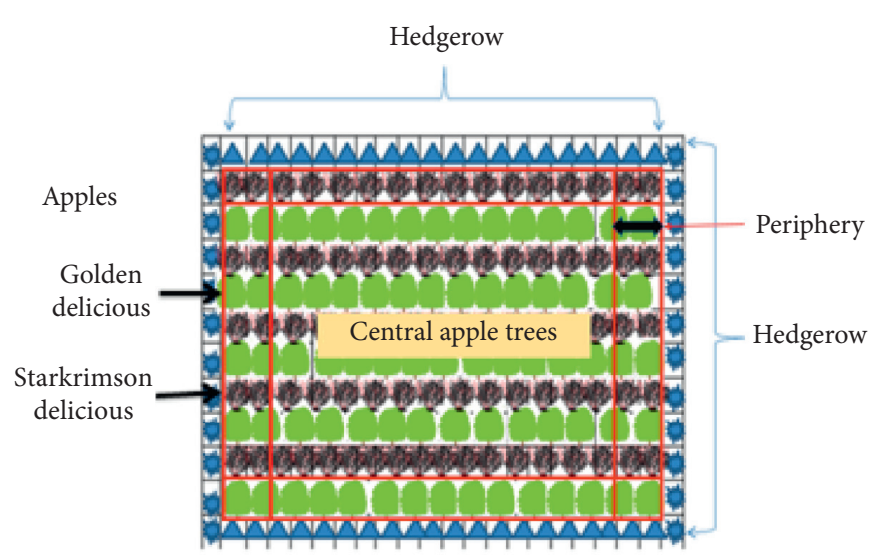

Nest morphology

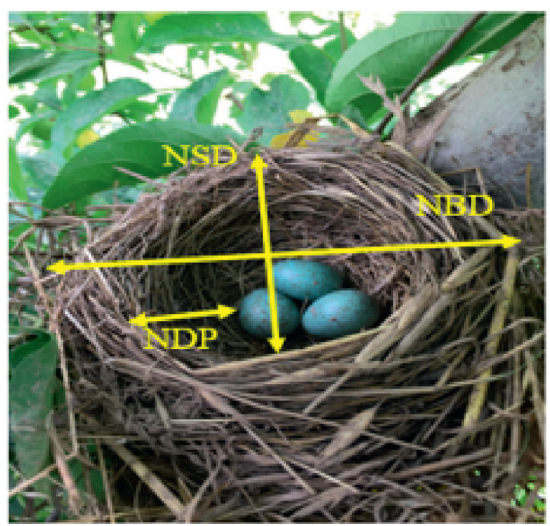

Nest placement

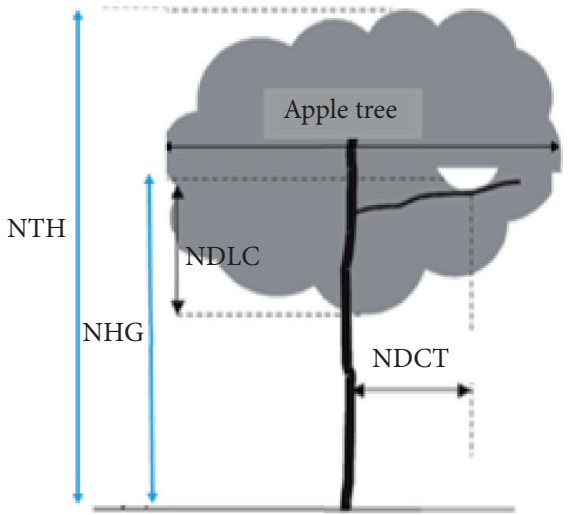

Nesting parameters

NTH: nesting-tree height,

NHG: nest height above the ground,

NDLC: lower canopy distance,

NDCT: distance of nest to tree center,

NBD: nest big diameter,

NSD: nest small diameter,

NDP: nest cup depth.

Figure 2: Nesting sites, placement, and morphology of the Blackbird in the Ait Ayach zone. 
On the other hand, inside apple orchards, nests were placed mainly in the center ( $67.56 \%$ of nests) compared to the marginal trees (32.43\% of nests).

Nest height above the ground was $214.15 \pm 0.09 \mathrm{~cm}$, $95.4 \pm 0.09 \mathrm{~cm}$ far from the tree center trunk, and the distance to the lower canopy was $95.4 \pm 0.09 \mathrm{~cm}$. Nest height was related to the height of the supporting tree (Figure 3 ).

3.2. Nest Morphology. Blackbird nests are built from twigs of different natures, including dry leaves, stems, and roots, and surrounding a circular cup creased with small dry grass. The internal cup is walled by the mud that isolates clutches from plant materials. Generally, nests were cup-shaped, with an external diameter of $8.30 \pm 0.29 \mathrm{~cm}(n=74$ nests $)$, an internal diameter of $7.03 \pm 0.29 \mathrm{~cm}$, and a cup depth of $5.82 \pm 0.35 \mathrm{~cm}$. Both diameters were positively correlated (Table 1).

3.3. Breeding Chronology. The breeding chronology of the European Blackbird in apple orchards, including nesting, laying, and hatching dates, at Oukhaja is summarized in Figure 4. After the formation of breeding pairs, initiation of nest construction began during the last week of April, followed by laying of first eggs on the first week of May. The first chicks were documented on the second week of May. Laying and hatching dates were controlled by dates of nest construction (Figure 5 and Table 2).

On the other hand, the nesting time dated from the last week of April to the third week of June. The laying period was from the first week of May to the last week of June. The hatching period was between the second week of May and the last week of June. Finally, the breeding period (first nest to the last chicks) was between April and August.

3.4. Breeding Success. All monitored nests were active after construction (Table 3). Among the 155 documented eggs, $88.38 \%$ were hatched in apple orchards. The fledging success rate was $78.10 \%$. In total, $69.03 \%$ of chicks have been emancipated (survived chicks/laid eggs). However, success rates were higher during nesting and laying phases $(n=15$, $F=699.14, \mathrm{Df}=2, P<0.001)$.

Clutches were menaced by a variety of threats. In summary, $15.9 \%$ of clutches were unsuccessful due to predators $(8.10 \%$ of nests, $8.75 \%$ of eggs, and $8.02 \%$ of chicks), and $14.35 \%$ of clutches were failed due to nest desertion caused by anthropological disturbance $(2.70 \%$ of nests, $1.93 \%$ of eggs, and $5.10 \%$ of chicks). Equally, $8.75 \%$ of chicks were dead, and $1.93 \%$ of unhatched eggs (Figure 6).

\section{Discussion}

To our knowledge, this is the first research of the breeding biology of the Common Blackbird Turdus merula in Morocco. Our focal objective was to provide comprehensive information on the nesting sites, breeding chronology, and breeding success rates of this widely distributed species. We acquired valuable and original data describing the breeding habitat use and the reproductive performance of the Common Blackbird. These data are the first and only provided results associated with the Common Blackbird in Morocco and the entire Northwest African area, which is of great interest for the application of potential monitoring of the widespread Moroccan Blackbird population.

To date, it is known that the Common Blackbird is a resident-breeding bird in Morocco and North Africa since it was recorded in agroecosystems and woodlands. Equally, in our piloting study, nests of Turdus merula were found inside apple orchards and surrounding woodlands. However, the higher percentages of nests were located inside the orchards in comparison with surrounding woody vegetation. Generally, the nesting preference toward apple orchards, mainly on Golden Delicious and Starkrimson Delicious, is suggested to be governed by the abundance of these farmlands in the area. Similar results were mentioned by Mansouri et al. in turtle doves in the same area, where nests were built mainly on the abundant apple trees.

Blackbirds placed their nests on an important height to protect their clutches and nestlings $[12,16,23]$. However, nest height was controlled by the height of supporting trees as mentioned by many authors [24]. On the other hand, Blackbird nests were cup-shaped with a medium size and built from interwoven twigs, leaves and roots, dry grass, and mud [25].

In our study, the Blackbird started nesting during the last week of April at Ait Ayach and egg laying during the first week of May, while in Algeria (North Africa) and Germany (Europe), breeding dates, including nesting and laying, were earlier during March and the beginning of April $[14,26]$. In Australia, breeding chronology started later in August [9]. Consequently, the breeding chronology varies depending on the geographical zone. On the other hand, at Ait Ayach, laying and hatching dates were related to nest construction chronology, which is logical since the nest is the support of eggs and nestlings [27].

The reproductive success rate of the Blackbird at Ait Ayach was high during all breeding phases counting nesting, incubation, and rearing. Only small portions of clutches, broods, and fledging were failed mainly due to predation attacks by reptiles such as horseshoe snake Hemorrhois hippocrepis and Montpellier snake Malpolon monspessulanus, and desertion of clutches due to human disturbance through pulverization of pesticides, which was applied two times per month. Similar results were mentioned in orange orchards in Algeria, where the causes of breeding failure were predation attacks by the lizards and snakes, nest deserted before hatching, nestling died, and brood desertion. In our case, the authors in $[6,8]$ have mentioned the abundance of reptiles and other predators, as well as the intensification of farming practices that cause loss of breeding attempts of avian species inside apple orchards. 


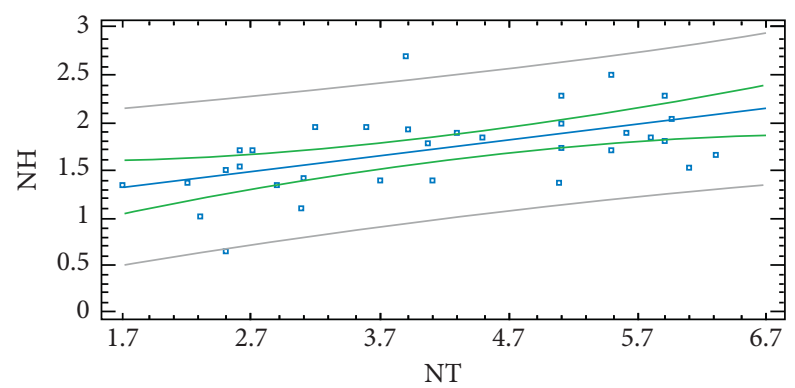

(a)

\begin{tabular}{|l|l|l|l|l|l|}
\hline Source & $\begin{array}{c}\text { Sum of } \\
\text { squares }\end{array}$ & Df & $\begin{array}{c}\text { Mean } \\
\text { square }\end{array}$ & F-ratio & P-value \\
\hline Model & 1.66056 & 1 & 1.66056 & 12.18 & 0.0014 \\
\hline Residual & 4.36291 & 32 & 0.136341 & & \\
\hline $\begin{array}{l}\text { Total } \\
\text { (corr.) }\end{array}$ & 6.02347 & 33 & & & \\
\hline
\end{tabular}

(b)

FIGURE 3: Linear model to describe the relationship between nest height above the ground (NH) and height of the supporting tree (NT).

TABLE 1: Correlations among nest dimensions of the Blackbird.

\begin{tabular}{lccc}
\hline & Internal diameter & External diameter & Cup depth \\
\hline Internal diameter & & 0.8861 & -0.1006 \\
$P$ value & & $<0.0001$ & 0.5946 \\
External diameter & 0.8861 & & 0.0493 \\
$P$ value & $<0.0001$ & & 0.7941 \\
Cup depth & -0.1006 & 0.0493 & 0.7941 \\
$P$ value & 0.5946 & & \\
\hline
\end{tabular}
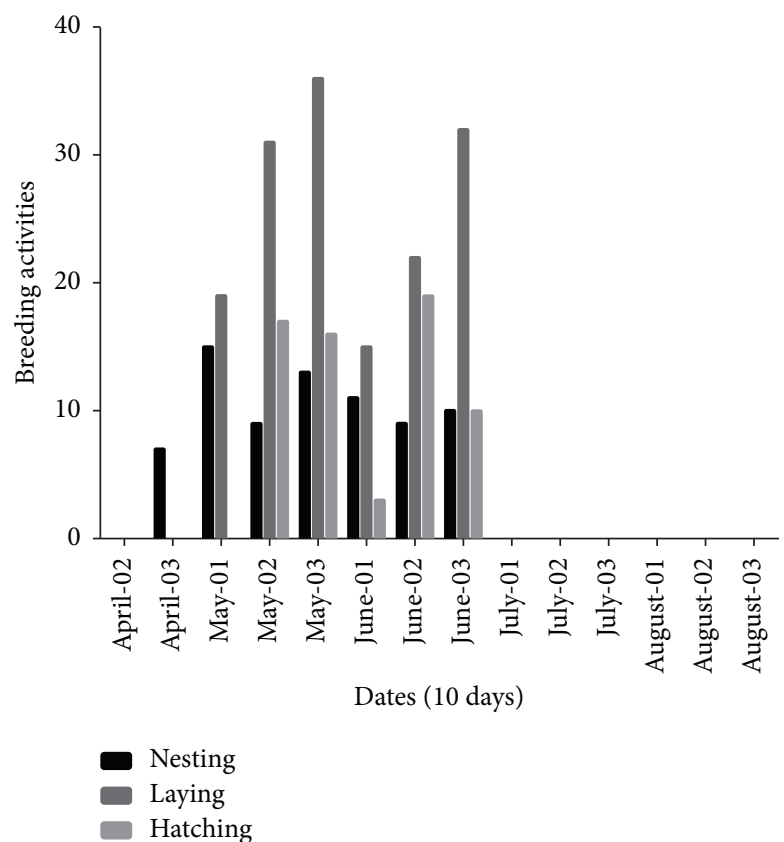

Figure 4: Breeding chronology of the Common Blackbird at the Ait Ayach zone. 


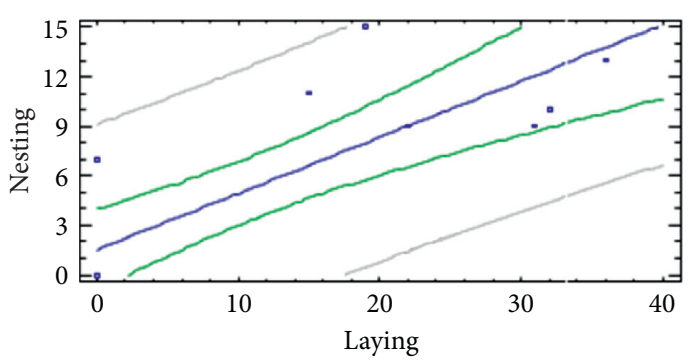

(a)

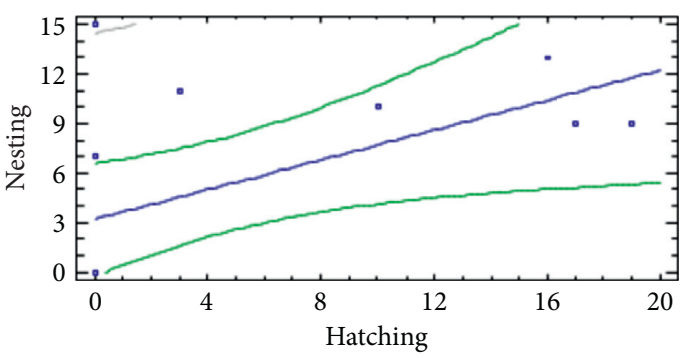

(b)

FIGURE 5: Relationship between nesting dates, laying, and hatching initiation.

TAвLE 2: General linear statistical model relating nesting, laying, and hatching dates.

\begin{tabular}{|c|c|c|c|c|c|}
\hline Source & Sum of squares & Df & Mean square & $F$-ratio & $P$ value \\
\hline Model (laying) & 304.488 & 1 & 304.488 & 28.03 & 0.0002 \\
\hline Residual & 130.369 & 12 & 10.8641 & & \\
\hline Total (corr.) & 434.857 & 13 & & & \\
\hline Model (hatching) & 144.86 & 1 & 144.86 & 5.99 & 0.0307 \\
\hline Residual & 289.997 & 12 & 24.1664 & & \\
\hline Total (corr.) & 434.857 & 13 & & & \\
\hline
\end{tabular}

TABLE 3: Breeding success and failure factor between breeding phases of the Blackbird at Ait Ayach.

\begin{tabular}{|c|c|c|c|}
\hline \multicolumn{4}{|c|}{ Ait Ayach } \\
\hline Phase & Parameter & Number & $\%$ \\
\hline \multirow{5}{*}{ Nests } & Total & 74 & 100 \\
\hline & Active & 74 & 100 \\
\hline & Predated & 6 & 8.1 \\
\hline & Deserted & 2 & 2.7 \\
\hline & Destructed & 0 & 0 \\
\hline \multirow{6}{*}{ Eggs } & Total & 155 & 100 \\
\hline & Succeeded & 137 & 88.38 \\
\hline & Predated & 12 & 8.75 \\
\hline & Deserted & 3 & 1.93 \\
\hline & Destructed & 0 & 0 \\
\hline & Unhatched & 3 & 1.93 \\
\hline \multirow{5}{*}{ Chicks } & Total & 137 & 100 \\
\hline & Succeeded & 107 & 78.10 \\
\hline & Predated & 11 & 8.02 \\
\hline & Died & 12 & 8.75 \\
\hline & Deserted & 7 & 5.10 \\
\hline
\end{tabular}




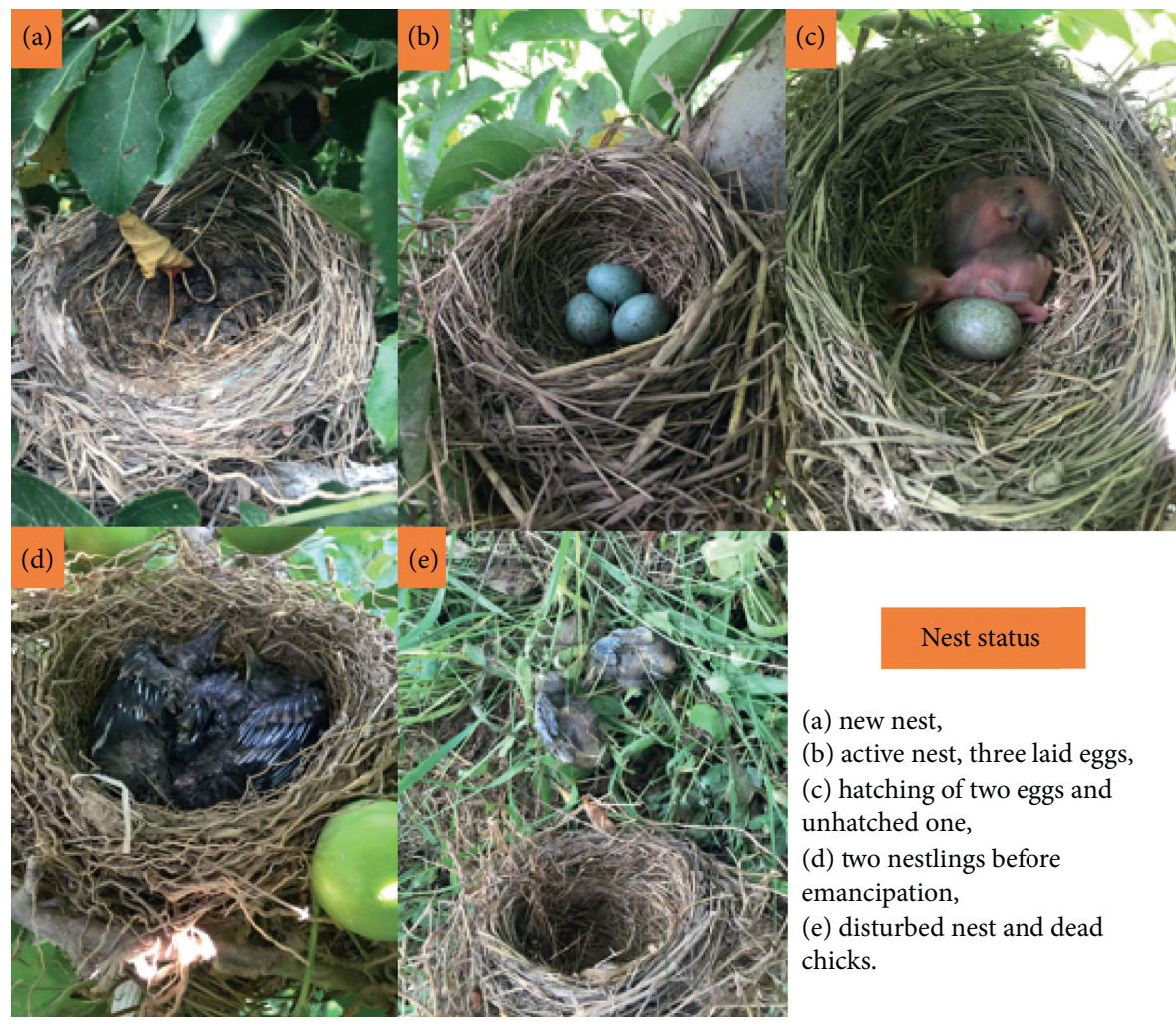

Figure 6: Status of the Common Blackbird clutches during 2016 breeding season.

\section{Conclusion}

In summary, we believe that our study provides the first and only detailed data on the breeding features of the Common Blackbird in Morocco and the whole Northwest African zone. In addition to their possible importance for a potential large-scale comparative study of the breeding ecology of the Blackbird, these data could be of great importance for the implementation of a workable and long-term monitoring plan of the Moroccan Blackbird population. Given that the European Blackbird is widely distributed in the Mediterranean zone and Western Palearctic, more studies on the population size, population trends, and foraging ecology are needed to establish proper management approaches.

\section{Data Availability}

All the necessary data are included within the article with clarity careful statement. The full data are available from the corresponding author upon reasonable request for any future studies.

\section{Conflicts of Interest}

The authors declare that they have no conflicts of interest.

\section{References}

[1] L. J. Ferreira and L. E. Lopes, "Breeding biology of the palebellied tyrant-manakin neopelma pallescens (aves: pipridae) in south-eastern Brazil," Journal of Natural History, vol. 52, pp. 29-30, 2018.

[2] L. E. Lopes, N. M. Heming, A. E. Jahn, D. D. F. Ferreira, O. B. Putaré, and M. Â. Marini, "Breeding biology of the white-throated kingbird (tyrannus albogularis) in Brazil and Bolivia," The Wilson Journal of Ornithology, vol. 130, no. 4, pp. 915-923, 2018.

[3] J. Balbontín and A. P. Møller, "Environmental conditions during early life accelerate the rate of senescence in a shortlived passerine bird," Ecology, vol. 96, no. 4, pp. 948-959, 2015.

[4] B.-E. Saether and O. Bakke, "Avian life history variation and contribution of demographic traits to the population growth rate," Ecology, vol. 81, no. 3, pp. 642-653, 2000.

[5] S. Ping and P. Ding, "History, status of monitoring land birds in Europe and America and countermeasures of China," Biodiversity Science, vol. 19, no. 3, pp. 303-310, 2011.

[6] I. Mansouri, M. Mounir, W. Squalli, L. Elhanafi, M. Dakki, and L. El Ghadraoui, "Migratory dates, breeding phenology, and reproductive success of European turtle doves between lowlands and highest breeding habitats in North Africa," International Journal of Zoology, vol. 2020, Article ID 8816577, 7 pages, 2020.

[7] A. Nefla, R. Ouni, S. Selmi, and S. Nouira, "Breeding biology of a relictual maghreb magpie (pica mauritanica) population in Tunisia," Avian Research, vol. 12, no. 1, 2021.

[8] I. Mansouri, W. Squalli, A. El Agy et al., "Avifauna diversity in the gate between humid atlas and saharan desert: Midelt province, Morocco," International Journal of Zoology, vol. 2021, Article ID 5557921, 10 pages, 2021.

[9] B. J. Kentish, P. Dann, and W. Kim, "Breeding biology of the common blackbird Turdus merula in Australia," Emu-Austral Ornithology, vol. 95, no. 4, pp. 233-244, 1995. 
[10] X. Lu, "Reproductive ecology of blackbirds (Turdus merula maximus) in a high-altitude location, Tibet," Journal of Ornithology, vol. 146, no. 1, pp. 72-78, 2005.

[11] D. Wysocki, "Factors affecting the between-season divorce rate in the urban populations of the European BlackbirdTurdus merulain north-western Poland," Acta Ornithologica, vol. 41, no. 1, pp. 71-78, 2006.

[12] S. Selmi, "Determinants of distribution, abundance and reproductive success of the Common Blackbird (Turdus merula) in southern Tunisian oases," Ostrich, vol. 78, no. 2, pp. 309-313, 2007.

[13] G. Segelbacher, T. Sacher, A. Schwarzenberger, S. Woitsch, F. Bairlein, and T. Coppack, "Eight microsatellite loci characterised in the European blackbird, Turdus merula," Journal of Ornithology, vol. 149, no. 1, pp. 131-133, 2008.

[14] A. Zeraoula, T. Bensouilah, H. Brahmia, Z. Bouslama, M. Houhamdi, and A. Kerfouf, "Breeding biology of the European Blackbird Turdus merula in orange orchards," Journal of King Saud University-Science, vol. 28, no. 4, pp. 300-307, 2016.

[15] G. M. Siriwardena, S. R. Baillie, S. T. Buckland, R. M. Fewster, J. H. Marchant, and J. D. Wilson, "Trends in the abundance of farmland birds: a quantitative comparison of smoothed common birds Census indices," Journal of Applied Ecology, vol. 35 , no. 1 , pp. $24-43,1998$.

[16] A. Taberner, R. Tamarit, and J. A. Gil-Delgado, "Position of blackbird (Turdus merula) nests in orange trees," Avian Biology Research, vol. 5, no. 4, pp. 193-197, 2012.

[17] P. Bergier, M. Thévenot, A. Rihane, M. Aziz, E. Agbani, and A. Qninba, "Liste des oiseaux du Maroc," Mise à jour mai, vol. 14, pp. 43-68, 2017.

[18] D. Barreau and P. Bergier, "L'avifaune de la région de Marrakech (Haouz et Haut Atlas de Marrakech, Maroc). 3. Les espèces: Passereaux," Avifaune Région Marrakech Haouz Haut Atlas Marrakech Maroc 3 Espèces Passereaux, vol. 69, no. 2, pp. 261-309, 2001.

[19] J. Pretty and Z. P. Bharucha, "Sustainable intensification in agricultural systems," Annals of Botany, vol. 114, no. 8, pp. 1571-1596, 2014.

[20] M. Amezian, I. Thompson, K. Bensusan, J. Cortes, A. Louah, and A. Qninba, "On regular wintering of Eurasian Penduline Tits Remiz pendulinus in northern Morocco," Ostrich, vol. 82, no. 1, pp. 39-42, 2011.

[21] I. Mansouri, D. Mohamed, and A. Mouadrochdi, "The first survey of European serinchick's growth under natural conditions: which organs get maturity before nest leaving," $R e$ search Journal of Pharmaceutical Biological and Chemical Sciences, vol. 9, no. 5, pp. 64-73, 2018.

[22] I. Mansouri, D. Ousaaid, W. Squalli, H. Sqalli, L. E. Ghadraoui, and M. Dakki, "The turtle dove (Streptopelia turtur) in Midelt plain, Morocco: nesting preferences and breeding success versus the impact of predation and agricultural practices," Journal of Animal Behaviour and Biometeorology, vol. 8, no. 3, pp. 206-214, 2020.

[23] D. Wysocki, Ł. Jankowiak, J. L. Greño, A. Cichocka, I. Sondej, and B. Michalska, "Factors affecting nest size in a population of Blackbirds Turdus merula," Bird Study, vol. 62, no. 2, pp. 208-216, 2015.

[24] K. L. Borgmann and A. D. Rodewald, "Nest predation in an urbanizing landscape:the role of exotic shrubs," Ecological Applications, vol. 14, no. 6, pp. 1757-1765, 2004.

[25] L. E. Biddle, D. C. Deeming, and A. M. Goodman, "Morphology and biomechanics of the nests of the common blackbird Turdus merula," Bird Study, vol. 62, no. 1, pp. 87-95, 2015.

[26] A. Russ, T. Lučeničová, and R. Klenke, "Altered breeding biology of the European blackbird under artificial light at night," Journal of Avian Biology, vol. 48, no. 8, pp. 1114-1125, 2017.

[27] W. Squalli, I. Mansouri, M. Dakki, and F. Fadil, "Nesting habitat and breeding success of Fulica atra in tree wetlands in Fez's region, central Morocco," Journal of Animal Behaviour and Biometeorology, vol. 8, no. 4, pp. 282-287, 2020. 